- Screened positive children fail to receive appropriate dental care.

- School dental screening fails to reduce socio-economic inequalities.

- Can school dental screening in its current format be justified?

- Can access to schools afforded by dental screening be better used?

\title{
The effectiveness of school dental screening: dental attendance and treatment of those screened positive
}

\author{
K. M. Milsom, ${ }^{1}$ A. G. Threlfall, ${ }^{2}$ A. S. Blinkhorn, ${ }^{3}$ P. I. Kearney-Mitchell, ${ }^{4}$ K. M. Buchanan ${ }^{5}$ and M. Tickle ${ }^{6}$
}

\begin{abstract}
Objective To determine dental attendance and treatment outcomes following two models of dental screening.

Design An observational prospective cohort study.

Setting Infant, primary and junior schools in the North West of England. Subjects Children aged six to nine years at the start of the study. Interventions Subjects received a screening examination according to either a 'Traditional model' or 'New model' of school dental screening Main outcome measures Attendance at a dentist within four months of the intervention and treatment received by children referred via the 'New model' with caries in their permanent teeth.

Results In the 'New model' of school dental screening $46 \%$ of screened positive and $41 \%$ of screened negative children attended a dentist during the study period. Some $44 \%$ of children referred with caries in permanent teeth attended a dentist and $53 \%$ of those attending received treatment for the referred condition. Larger proportions of children from disadvantaged backgrounds were screened positive but higher proportions of children from more affluent backgrounds attended the dentist and subsequently received treatment.

Conclusion School dental screening has a minimal impact on dental attendance and only a small proportion of screened positive children receive appropriate treatment. The programme fails to reduce inequalities in utilisation of dental services.
\end{abstract}

\footnotetext{
$1^{*}$ Consultant in Dental Public Health/Director National Oral Health Unit, Department of Dental Research and Development, Halton NHS Primary Care Trust, Moston Lodge, Countess of Chester Health Park, Liverpool Road, Chester CH2 1UL; ${ }^{2}$ Post-Doctoral Research Fellow, The National Oral Health Unit, Manchester Dental School, Higher Cambridge Street, Manchester. ${ }^{3}$ Professor of Child Dental Health, The National Ora Health Unit, Manchester Dental School, Higher Cambridge Street, Manchester; ${ }^{4}$ Dental Public Health Co-ordinator, Department of Dental Research and Development, Halton NHS Primary Care Trust, Moston Lodge, Countess of Chester Health Park, Liverpool Road, Chester CH2 1UL; ${ }^{5}$ Research Project Manager, Department of Dental Research and Development, Halton NHS Primary Care Trust, Moston Lodge, Countess of Chester Health Park, Liverpool Road, Chester CH2 1UL; ${ }^{6}$ Senior Lecturer/Consultant in Dental Public Health, The National Oral Health Unit, Manchester Dental School, Higher Cambridge Street, Manchester

*Correspondence to: Dr Keith Milsom

Email: keith.milsom@cahc-tr.nwest.nhs.uk
}

\section{Refereed paper}

Accepted 14 June 2005

DOI: 10.1038/sj.bdj.4813724

๑ B British Dental Journal 2006; 200: 687-690

\section{INTRODUCTION}

A recently completed cluster randomised control trial of school dental screening targeted at children aged six to nine years living in the North West of England could demonstrate no benefit in terms of reducing the levels of untreated dental disease or increasing dental attendance at the population level. ${ }^{1}$ Screening can only be regarded as being successful if it offers health improvement either for the population as a whole, or the screened positive individual, or both. ${ }^{2}$ Although no benefit was observed at the population level, it is possible that school dental screening has a role in reducing dental health inequalities by encouraging individual children with dental needs to attend and receive appropriate treatment. Whilst dental caries is directly associated with deprivation, routine dental attendance is less likely amongst socially disadvantaged children., ${ }^{3,4}$ Increasingly, school dental screening is seen as a vehicle for bringing children with dental needs into contact with dental services ${ }^{5,6}$ and so it is particularly important to determine if dental screening can help disadvantaged children with untreated dental disease to obtain appropriate treatment

Previous studies of school dental screening have assessed its effects in terms of stimulating dental attendance ${ }^{7,8}$ and it has been argued that this dental public health measure is effective at stimulating attendance amongst the socially deprived, ${ }^{9}$ however, no studies have pursued the process of school dental screening from the screening intervention to the identification of the number of screened positive children that go on to receive appropriate treatment.

This study reports the dental attendance patterns, by socio-economic status, of children that were screened positive using two screening models. It also reports the treatment outcomes for those children, screened using one of the models, who were referred because they had caries in their permanent teeth.

\section{METHOD}

This study used data from the populations in two arms of a four-arm cluster randomised control trial. The methodology of the overall randomised control trial, including population selection and the interventions used, are described in detail elsewhere. ${ }^{1}$ The trial population was made up of 17,098 children 
aged six to nine years attending 169 state maintained schools in Runcorn, Widnes, St Helens and Knowsley. The study reported here involves the children randomly allocated to two arms of the trial, namely:

- A 'Traditional model' of school dental screening

- A 'New model' of school dental screening

and reports the children's attendance and treatment patterns following the screening intervention.

The 'Traditional model' of school dental screening, used the model already in place in the study area. In this model, children were referred from screening if in the opinion of the screening dentist they required dental treatment. A letter was sent to the parents of screened positive children informing them that their child would benefit from a dental examination. This approach is commonly used across England and Wales. ${ }^{10,11}$ The 'New model' involved training and calibrating the screening dentists in the identification of an agreed set of clinical criteria, any of which would trigger a referral following screening. The clinical criteria were agreed by a random sample of dentists practising in the North West of England ${ }^{12}$ and included caries in the permanent dentition, the presence of sepsis, untreated trauma to permanent anterior teeth and the presence of gross plaque or calculus. The criteria did not include caries in the primary dentition. At the screening examination the nature of the referral criteria was recorded.

Children in the two populations that attended the General Dental Service (GDS) and Personal Dental Service (PDS) were identified by a fuzzy matching of study data with records held by the Dental Practice Board (DPB). For those children that attended the Community Dental Service (CDS), hand searching of clinical records was undertaken. A child was defined as having attended a dentist if they attended a GDS, PDS or CDS dentist in the four-month period following the screening examination. Analyses of attendance included the populations that received the 'Traditional model' and the 'New model' of screening.

Analyses involving treatment provision were confined to the 'New model' population only, as the reason for referral was identified at the screening examination. In particular the study focussed on those children recorded by the screening dentist as having untreated caries in their permanent teeth. Screened positive children in the 'New model' group, with caries in their permanent teeth and who attended a dentist were then matched against the DPB's databases which identify the treatment received by GDS and PDS patients. The treatment provided to those children who attended the CDS was identified by hand searching case notes.

An Index of Multiple Deprivation summary score (IMD 2004) ${ }^{13}$ was attached to each child's record by reference to the child's home postcode. Using these scores, the population was divided into approximately equal quintiles, so that quintile one included the children living at addresses in the most affluent areas and quintile five included children living at addresses in the least affluent areas.

Descriptive analyses were performed. The number and proportion of subjects that were screened and attended a dentist were calculated. The treatment patterns for those children allocated to the 'New model' of screening, who were referred for caries in their permanent teeth, were also identified. In addition, referral and attendance rates following school dental screening were calculated according to quintiles of multiple deprivation as were the number and proportion of children referred and treated for caries in the permanent dentition.

\section{RESULTS}

In total 8,505 children were included in the study, 4,418 in the 'Traditional model' and 4,087 in the 'New model'. Table 1 shows the number of children referred to a dentist from the 'Traditional' and 'New' models of dental screening and the number of those

\begin{tabular}{|c|c|c|c|}
\hline Trial arm & Result of screen & $\begin{array}{l}\text { Number in } \\
\text { group }\end{array}$ & $\begin{array}{l}\text { Number (\%) } \\
\text { attended }\end{array}$ \\
\hline \multirow{2}{*}{$\begin{array}{l}\text { Traditional } \\
\text { screening }\end{array}$} & $\begin{array}{l}\text { Screened positive } \\
\text { (referred) }\end{array}$ & 1,208 & $576(48)$ \\
\hline & $\begin{array}{l}\text { Screened negative } \\
\text { (or not screened) }\end{array}$ & 3,210 & $1,262(39)$ \\
\hline \multirow{2}{*}{$\begin{array}{l}\text { New } \\
\text { Model } \\
\text { Screening }\end{array}$} & $\begin{array}{l}\text { Screened positive } \\
\text { (referred) }\end{array}$ & 571 & $260(46)$ \\
\hline & $\begin{array}{l}\text { Screened negative } \\
\text { (or not screened) }\end{array}$ & 3,516 & 1,435 (41) \\
\hline Total & & 8,505 & $3,533(42)$ \\
\hline
\end{tabular}

\begin{tabular}{|c|c|c|c|}
\hline IMD quintile & $\begin{array}{l}\text { Number } \\
\text { screened }\end{array}$ & $\begin{array}{l}\text { Number referred } \\
\text { (percentage of those } \\
\text { screened) }\end{array}$ & $\begin{array}{l}\text { Number attending a } \\
\text { dentist (percentage } \\
\text { of those referred) }\end{array}$ \\
\hline 1 Most affluent & 692 & $65(9.4)$ & $40(62)$ \\
\hline 2 & 796 & $125(16)$ & $67(54)$ \\
\hline 3 & 735 & $123(17)$ & $45(37)$ \\
\hline 4 & 670 & $134(20)$ & $60(45)$ \\
\hline 5 Deprived & 491 & $113(23)$ & 44 (39) \\
\hline IMD score unknown & 52 & $11(21)$ & $4(36)$ \\
\hline All children & 3,436 & $571(17)$ & $260(46)$ \\
\hline
\end{tabular}

referred that were judged to have attended. A smaller proportion of children were referred in the 'New model' $(\mathrm{N}=571,14 \%)$ compared to the 'Traditional model' ( $N=1,208,27 \%)$. Within the 'Traditional' model of screening, 48\% of referred children actually attended, whilst 39\% of children who were not referred also attended a dentist within four months of the screening intervention, a difference of 9\%. A similar picture emerges when the 'New model' is considered, with $46 \%$ of screened positive children attending, and $41 \%$ of children that were not referred also attending a dentist.

In total, 4,087 children were randomised to the 'New model' and 3,436 children (84\%) screened. Table 2 describes the referral and attendance pattern of those children screened in the 'New model' according to their socio-economic quintile. An IMD score was not available for 52 children that were screened in the 'New model' due to missing postcodes. The children in the most affluent quintile (quintile one) were less likely to be referred from dental screening than children in the most deprived quintile, but once referred, children in the most affluent quintile were more likely to attend a dentist than children in the most deprived quintile.

Table 3 describes the conditions for which the 571 children screened positive in the 'New model' were referred. Fifty-two children were referred for more than one condition of which 45 had caries in the permanent dentition. In total 303 children were referred via the 'New model' because they had caries in the permanent dentition.

Table 4 describes the treatments provided by each service for the children that attended following a referral for caries in the permanent dentition. In total, 133 of the 303 referred children attend- 


$\begin{aligned} & \text { Table } 3 \text { The number and percentage of children that were referred in the } \\
& \text { 'New model' of dental screening by reason for referral }\end{aligned}$
\begin{tabular}{ll}
\hline Reason for referral & Number of children referred (\%) \\
\hline Caries in permanent teeth alone & $258(45)$ \\
\hline Sepsis alone & $236(41)$ \\
\hline Trauma alone & $2(0.4)$ \\
\hline Plaque alone & $22(4)$ \\
\hline More than one reason & $52(9)$ \\
\hline No reason recorded & $1(0.2)$ \\
\hline Total & 571 \\
\hline
\end{tabular}

ed a dentist in either the GDS, CDS, or PDS. Just over half of those attending $(N=70,53 \%)$ received treatment to carious permanent teeth, with restoration being the most common intervention. The majority of those children attending following referral for caries in their permanent teeth $(108,81 \%)$ attended the GDS and 55 of these children (51\%) received some treatment for carious permanent teeth. By comparison, 13 children (10\%) attended the CDS and six (46\%) of these children received dental treatment to their permanent teeth.

Table 5 considers the treatment delivered for those children referred for caries in their permanent dentition, according to socioeconomic quintile. Six children were excluded from this analysis because they could not be assigned an IMD score. As with attendance, socio-economic status had an impact on the utilisation of dental services following a referral from school dental screening. Children in the most affluent IMD quintile (quintile one) were twice as likely (34\%) to receive treatment for their carious permanent teeth than were children in the most deprived quintile (16\%).

\section{DISCUSSION}

The National Screening Committee ${ }^{2}$ requires any screening programme to benefit the community that the programme is applied to and/or the screened positive population. The results of the previously published cluster randomised control of school dental screening ${ }^{1}$ could demonstrate no benefit at the population level. The study reported here describes the outcomes for those who were screened positive. The results suggest that screening also fails to produces worthwhile benefits for the screened positive population.

This study demonstrates that the screening programme breaks down at two points; less than half of screened positive children attend the dentist and of those that do attend less than a quarter receive appropriate treatment. Similar findings have been reported in other studies ${ }^{14,15}$ and the reasons why uptake and utilisation of care is disappointing can only be speculated upon. Qualitative work ${ }^{16}$ suggests that parents value the concept of screening but
Table 5 Children referred from 'New model' dental screening with caries in the permanent dentition who received treatment to the permanent dentition by Index of Material Deprivation quintile

\begin{tabular}{lll}
\hline IMD quintile & $\begin{array}{l}\text { Number referred for caries in } \\
\text { the permanent dentition }\end{array}$ & $\begin{array}{l}\text { Number }(\%) \text { received } \\
\text { treatment for caries in the } \\
\text { permanent dentition }\end{array}$ \\
\hline 1 Most affluent & 35 & $12(34)$ \\
\hline 2 & 67 & $18(27)$ \\
\hline 3 & 69 & $13(19)$ \\
\hline $\mathbf{5}$ & 76 & $18(24)$ \\
\hline 5 Deprived & 50 & $8(16)$ \\
\hline Total & 297 & $69(23)$ \\
\hline
\end{tabular}

it is clear that many parents struggle to ensure that their child attends the dentist when they are not experiencing symptoms. This may be partly due to dental care being a low priority in some households, particularly those in disadvantaged areas. ${ }^{17}$ It is also likely that part of the failing is due to how the screening programme is delivered. The methodologies used in this study were not inherently different from how school dental screening is delivered across England and Wales. ${ }^{10,11}$ Importantly, unlike other national screening programmes, dental screening services do not systematically collect comprehensive data ${ }^{10,11}$ on post screening dental attendance, therefore identifying failures in local programmes is not possible. There is some evidence to suggest that vigorous follow-up of screened positive children does lead to improved attendance levels. ${ }^{9,18}$ However, the acceptability to parents and the cost effectiveness of putting significant resources into elaborate follow up procedures would need to be scientifically assessed.

The low level of post screening treatment reported here has been reported in other studies. ${ }^{19}$ Studies have demonstrated absolute consensus amongst primary care dentists that caries in the permanent dentition should trigger a referral from dental screening, ${ }^{12,20}$ so the reasons why a large proportion of screened positive children failed to receive treatment are difficult to account for, especially as dental waiting times in the study area were modest. It could be that children attend for consultation and treatment planning but then fail to return for scheduled treatment. It could also be that in some cases there was a delay in providing definitive treatment, for example some children may have been referred for a GA at a later stage in their development. Further research is needed to identify the barriers that prevent screened positive children from receiving treatment for caries in the permanent dentition.

The most worrying aspect of this study is the potential for screening to amplify existing inequalities in utilisation of dental health care. This study clearly demonstrates that the screening test can identify children with untreated disease, large proportions of whom come from disadvantaged backgrounds. However, these

\begin{tabular}{|c|c|c|c|c|c|c|}
\hline \multirow[t]{2}{*}{ Service attended } & \multirow{2}{*}{$\begin{array}{l}\text { Number attending a } \\
\text { dentist }\end{array}$} & \multirow{2}{*}{$\begin{array}{l}\text { Number receiving } \\
\text { treatment to permanent } \\
\text { dentition }\end{array}$} & \multicolumn{4}{|c|}{ Treatment provided to the permanent dentition } \\
\hline & & & restoration & extraction & $\begin{array}{l}\text { restoration and } \\
\text { extraction }\end{array}$ & fissure seal alone \\
\hline GDS alone & 108 & 55 & 38 & 1 & 1 & 15 \\
\hline CDS alone & 13 & 6 & 2 & 4 & 0 & 0 \\
\hline PDS alone & 8 & 5 & 5 & 0 & 0 & 0 \\
\hline More than one service & 4 & 4 & 3 & 0 & 1 & 0 \\
\hline Any service & 133 & 70 & 48 & 5 & 2 & 15 \\
\hline
\end{tabular}


children are less likely to access dental services or obtain dental treatment than their more affluent peers. These results agree with the findings of other studies in the literature ${ }^{4}$ and this is perhaps the most disappointing finding of the study, as one of the oftencited aims of screening is to reduce inequalities. Preston et al. ${ }^{16}$ reported that parents of deprived children felt reassured that their children had received a dental examination. The results of the study reported here suggest that this reassurance may be ill founded as the majority of screened positive children from deprived areas do not receive appropriate treatment following screening.

This study raises questions about the ethical basis of continuing to provide an ineffective screening programme. This, along with the opportunity costs of providing an ineffective programme when many parts of the country are experiencing dental access problems should to be considered carefully by policy makers and health care commissioners. Screening provides dentists with a valuable statutory access to schools; before this privilege is withdrawn the NHS needs to consider whether the statutory access to schools and the current screening workforce can be used more effectively to improve the dental health of children.

\section{CONCLUSION}

The results of this large prospective study of school dental screening suggest that the majority of screened positive six to nine year-old children living in the North West of England, derived little benefit from the school dental screening programme in terms of attending the dentist, and receiving treatment for their carious permanent teeth. School dental screening also fails to address inequalities in the prevalence of untreated disease and utilisation dental services.

The authors would like to thank: The children who participated in the trial, the head teachers who allowed the study to be delivered and the dental epidemiological and screening teams who delivered the fieldwork; The Dental Practice Board and The Merseyside and Cheshire RED Support Unit and in particular Dr Ruth Hunter; and Professor R. Ireland for his assistance in the development of the 'New model' of school dental screening. The study was funded by the North West Region Department of Health Research and Development programme. The Views and opinions expressed in this paper do not necessarily reflect those of the funding authority.

1. Milsom K M, Blinkhorn A S, Threlfall A et al. The effectiveness of school dental screening: a cluster randomised controlled trial. J Dent Research (in press).

2. Department of Health. Second Report of the UK National Screening Committee. London: Department of Health, 2000.

3. O'Brien M. Children's dental health in the United Kingdom 1993. Office of Populations Censuses and Surveys. London: 1994

4. Tickle M, Williams M J, Jenner A M, Blinkhorn A S. The effects of dental attendance and socioeconomic status on dental caries experience and treatment patterns in 5year-old children. Br Dent J 1999; 186: 135-137.

5. Department of Health and Social Security. Towards Better Dental Health guidelines for the future. The Report of the Dental Strategy Review Group. London: Department of Health, 1981.

6. Department of Health. Modernising NHS Dentistry - Implementing the NHS Plan. London: Department of Health, 2000.

7. Zoitopoulos H. An evaluation of the effectiveness of school dental inspection. Birmingham: University of Birmingham, 1989. MCDH Thesis.

8. Donaldson M, Kinirons M. Effectiveness of the school dental screening programme in stimulating dental attendance for children in need of treatment in Northern Ireland. Community Dent Oral Epidemiol 2001; 29: 143-149.

9. Zarod B K, Lennon M A. The effect of school dental screening on dental attendance. The results of a randomised trial. Community Dental Health 1992; 9: 361-368.

10. Mander C. 'Dental Screening of School Children'. Bristol: South West Research and Development Directorate, 1995.

11. Threlfall A, Milsom K M, Catleugh M et al. School Dental Screening in the Community Dental Services of England and Wales in 2003. Community Dent Health (in press).

12. Kearney-Mitchell PI, Milsom K M, Blinkhorn A S, Tickle M. Using the Delphi technique to develop referral criteria for use in a randomised controlled trial measuring the effectiveness of school dental screening. Br Dent J 200; 9: 509-512.

13. Office of the Deputy Prime Minister. The English Indices of Deprivation 2004 Available at http://www.opdm.gov.uk

14. Mattin D J. Benefits and cost of a dental screening programme in Southampton London: University of London, 1994. MSc Thesis.

15. Kay E J. A report on school dental screening in South Glamorgan. South Glamorgan Health Authority, 1993

16. Preston S T, Davies G M Craven $R$. An investigation of parents' attitudes to dental health and school dental screening. Community Dent Health 2001; 18: 105-109.

17. Tickle M, Crossley M L, Milsom K M et al. Dental screening in UK schools: identifying the views of parents/carers, teachers and school nurses. Br Dent $J$ (in press).

18. Harding M, Taylor G. The outcome of school dental screening in two suburban districts of Greater Manchester, UK. Community Dental Health 1993; 10: 269-275.

19. Morrant A M, Holloway P J, Taylor G O. A novel school dental screening programme. Community Dental Health 1995; 12: 128-132.

20. Milsom K M, Tickle M, Jenner A, Moulding G. The identification of agreed criteria for referral following the dental inspection of children in the school setting. Br Dent $J$ 1999; 186: 37-40 